\title{
PEROXIDASES E FENÓIS TOTAIS EM TECIDOS DE PORTA-ENXERTOS DE Prunus sp. NOS PERÍODOS DE CRESCIMENTO VEGETATIVO E DE DORMÊNCIA
}

\author{
PEROXIDASES ACTIVITY AND TOTAL PHENOLS IN THE TISSUE ROOTSTOCK \\ OF Prunus sp. IN THE VEGETATIVE DEVELOPMENT AND REST PERIODS
}

\author{
Alexandre Couto Rodrigues ${ }^{1}$ Ângela Campos Diniz ${ }^{2}$ José Carlos Fachinello $^{2}$ \\ João Baptista da Silva $^{2}$ João Luiz Carvalho Faria ${ }^{2}$
}

\section{RESUMO}

A atividade de peroxidases e a concentração de fenóis apresentam uma grande importância na união entre o enxerto e o porta-enxerto, podendo, desta forma, influenciar as respostas de estresse da incompatibilidade no processo de enxertia. $O$ presente trabalho objetivou quantificar a atividade das peroxidases e dos fenóis totais em cultivares de Prunus sp. Amostras de casca e de lenho foram processadas e quantificadas por espectrofotometria, a partir dos porta-enxertos de pessegueiros GF 677, Okinawa, Capdeboscq e Aldrighi e de ameixeiras Mirabolano e Marianna comum, cultivados nos viveiros do Departamento de Fitotecnia da FAEM/UFPel. Concluiu-se que a atividade das peroxidases e dos fenóis totais varia entre porta-enxertos, período de crescimento e tipo de tecido; a maior atividade das peroxidases e dos fenóis totais ocorre nos porta-enxertos Mirabolano e Marianna; a atividade das peroxidases e dos fenóis totais é maior na casca do que no lenho; no período de dormência, ocorre maior atividade das peroxidases e menor quantidade de fenóis totais, sendo o inverso no período vegetativo.

Palavras-chave: pessegueiro, ameixeira, metabolismo.

\section{SUMMARY}

The peroxidase activities and total phenols present a great importance in the union between the stock and the rootstock, and this is a way to evaluate the response to stress of the incompatibility in the graft process. This work aimed to quantify peroxidase activities and total phenols in order to verify its influence on the physiological and biochemical processes of
Prunus sp. cultivars grafting. Those metabolic processes the samples in the bark and wood were processed and quantified by spectrophotometry, starting from peach rootstock GF 677, Okinawa, Capdeboscq and Aldrighi; and plum rootstock cv. Mirabolano and Marianna Comum, from nurseries of the Department of Plant Science of FAEM/UFPel. It is concluded that: peroxidase and the total phenol activities vary among rootstocks, growth period and tissue type; the highest peroxidase activities and total phenols occurred in Mirabolano and Marianna rootstoks; the peroxidase activities and total phenols were higher in the bark than in wood; the largest peroxidase activities occurs during the rest period and lower amount of total phenols, being the contrary in the vegetative period.

Key words: tree peach, tree plum, metabolism.

\section{INTRODUÇÃO}

A quantificação da atividade das peroxidases e dos fenóis totais é importante para verificar as suas influências nos processos fisiológicos e bioquímicos da enxertia de cultivares de Prunus sp. Segundo SANTAMOUR (1992), para se obter o funcionamento do sistema vascular na união do enxerto, é necessário serem similares as peroxidases, tanto no enxerto como no portaenxerto, para que ocorra a produção de correlatas ligninas. Nas plantas que possuem semelhanças de peroxidases, raramente se encontram problemas de incompatibilidade.

\footnotetext{
${ }^{1}$ Engenheiro Agrônomo, Doutor, Faculdade de Agronomia Eliseu Maciel, Universidade Federal de Pelotas. E-mail: rcale@ufpel.tche.br. Autor para correspondência.

${ }^{2}$ Engenheiro Agrônomo, Mestre, Embrapa Clima Temperado, CP 403, 96001-970, Pelotas/RS.
} 
As peroxidases atuam na biossíntese do etileno, na lignificação, além da destruição das auxinas, devido ao fato de estas se apresentarem em muitas formas moleculares participando de diferentes reações bioquímicas (DENCHEVA \& KLISURKA, 1982).

As peroxidases são enzimas que utilizam o $\mathrm{H}_{2} \mathrm{O}_{2}$ para oxidar um grande número de doadores de hidrogênio, nos compostos fenólicos; esses participam de vários processos fisiológicos e desenvolvem seu papel na síntese da lignina e na incompatibilidade do enxerto. $\mathrm{Na}$ formação da lignina, as peroxidases fornecem $\mathrm{H}_{2} \mathrm{O}_{2}$ necessário para oxidação do ácido cinâmico e convertem o ácido ferúlico em diferúlico, o qual age na ponte de hemicelulose unindo o ácido cinâmico às proteínas e aos carboidratos da parede celular favorecendo a consolidação (GASPAR $\boldsymbol{e t}$ al., 1982). HARKIM \& OBST (1973) demonstraram a presença de peroxidases nas células lignificadas. Talvez, elas sejam as únicas enzimas que polimerizam os álcoois em lignina.

Observando a atividade das peroxidases em macieira, durante o enraizamento, DRUART et al. (1982) verificaram um aumento significativo destas durante a fase de indução, seguido por uma drástica redução, correspondendo à fase de iniciação. Além disso, o teor de fenóis variou inversamente à atividade das peroxidases.

Segundo MUSACCHI (1994), os fenóis fazem também uma ação de regularização da atividade auxínica. As auxinas são importantes nas primeiras fases da união entre o enxerto e o portaenxerto, agindo na rediferenciação vascular. Os compostos fenólicos são suficientes para regular a síntese da AIA-oxidase. Mais precisamente, o ácido cumárico e o ácido hidroxibenzólico (monofenóis) inibem o desenvolvimento da planta, porque ativam a oxidação das auxinas, enquanto os polifenóis, como o ácido cafêico, inibem a oxidação das auxinas, promovendo o crescimento das plantas.

Sendo a atividade das peroxidases e dos fenóis totais importantes na união do enxerto e porta-enxerto, este trabalho foi realizado com o objetivo de quantificá-las para avaliar as influências nos processos fisiológicos e bioquímicos da enxertia, em porta-enxertos de Prunus sp., em diferentes períodos de crescimento e tecidos.

\section{MATERIAL E MÉTODOS}

O material vegetal utilizado foi proveniente de cultivares de Prunus sp., propagadas nos viveiros do Departamento de Fitotecnia da Faculdade de Agronomia Eliseu Maciel.
A extração e análise das peroxidases (UE/min/g de tecido - peso fresco) e compostos fenólicos totais ( $\mathrm{mg} / \mathrm{g}$ de tecido - peso fresco) foram executadas no Laboratório de Fisiologia Vegetal da Embrapa Clima Temperado, localizado na BR 392 Km 72, em Pelotas, RS.

Quantificou-se a atividade das peroxidases (PO) e dos fenóis totais (FE) na casca e no lenho (fator B) dos porta-enxertos de pessegueiros Aldrighi, Capdeboscq, GF 677 e Okinawa e nas ameixeiras Mirabolano e Marianna comum (fator A), em plantas antes da enxertia com aproximadamente oito meses de idade e diâmetro do caule de $1 \mathrm{~cm}$. As amostras do tecido vegetal foram retiradas a $20 \mathrm{~cm}$ do colo de plantas, coletadas em 21/01/98, caracterizando o período vegetativo e 10/07/98, período de dormência, (fator C). As amostras foram congeladas em freezer a $-25^{\circ} \mathrm{C}$ e processadas gradativamente.

A quantificação da atividade das peroxidases foi determinada de acordo com a técnica descrita por MATSUNO \& URITANI (1972), padronizada no Laboratório, como segue: os extratos de todo material utilizado (casca e lenho), foram processados em temperatura inferior a $4^{\circ} \mathrm{C}$; pesou-se $3 \mathrm{~g}$ da casca e $3 \mathrm{~g}$ do lenho individualizados, triturouse em multi-processador por três minutos, com $100 \mathrm{~m} \ell$ de solução tampão extratora de fosfato monobásico e dibásico de potássio, $\mathrm{pH} \mathrm{7,} \mathrm{sendo} 40$ $\mathrm{ml}$ do tampão congelado e $60 \mathrm{~m} \ell$ líquido (abaixo de $4^{\circ} \mathrm{C}$ ), com adição de Polivinilpirrolidona; o extrato foi filtrado a vácuo em papel filtro Whatman $n^{0} 1$, sendo todo o filtrado coletado em vidrarias préresfriadas colocadas em bandejas com gelo durante a execução das atividades. Após a filtragem, os extratos foram colocados em frascos gelados e estocados em ultra-freezer para posterior análise. $\mathrm{O}$ descongelamento do material foi realizado, deixando-se de véspera, os extratos em geladeira (abaixo de $4 \mathrm{C}$ ), e o descongelamento final obtido em bandeja com gelo durante aproximadamente três horas, usando-se termômetro para acompanhar a temperatura; posteriormente centrifugou-se $35 \mathrm{~m} \ell$ do extrato por $20 \mathrm{~min}$ a 5000rpm em temperatura inferior a $4^{\circ} \mathrm{C}$ e o líquido sobrenadante foi transferido para outro recipiente e utilizado como extrato enzimático. Para o cálculo da atividade das peroxidases, as leituras foram realizadas após 10 minutos, em espectrofotômetro, modelo UV - 160 1PC Shimadzu, em comprimento de onda de $450 \mathrm{~nm}$. Uma unidade de enzima corresponde a um aumento na absorbância de 0,001 unidade ótica/minuto. Na prova em branco, usaram-se reagentes e água destilada (em vez do extrato enzimático). 
A quantificação dos compostos fenólicos totais foi realizada em duas fases. A primeira compreende o preparo do extrato e a extração dos fenóis totais - método adaptado de BIELESKI \& TURNER (1966) - composto das etapas de pesagem da matéria fresca, adição da solução metanol, clorofórmio e água (MCA), na relação 6/2,5/1,5 v/v respectivamente, trituração em almofariz à temperatura ambiente, centrifugada a $6000 \mathrm{~g}$ por $20 \mathrm{~min}$, e coletado o sobrenadante. Realizou-se nova extração do resíduo remanescente, adicionando-se mais $4 \mathrm{~m} \ell$ de MCA agitando-se em vórtex, centrifugado novamente a $6000 \mathrm{~g}$ por $20 \mathrm{~min}$ e o sobrenadante sendo adicionado ao primeiro, obtendo assim o extrato MCA. Ao extrato MCA foi adicionado $1 \mathrm{~m} \ell$ de clorofórmio e $1,5 \mathrm{~m} \ell$ de água, procedendo-se nova centrifugação a $6000 \mathrm{~g}$ por $15 \mathrm{~min}$ para separação das fases.

A segunda fase compreende a determinação de fenóis totais realizada pelo método adaptado de JENNINGS (1981), nas seguintes etapas: (i) preparou-se uma curva padrão, utilizandose quantidades conhecidas de tirosina (na faixa de 0 a $100 \mu \mathrm{g}$ ), e feita a curva de calibração a partir de uma solução com $100 \mu \mathrm{g}$ de tirosina/ml $(5 \mathrm{mg}$ de tirosina/50m $\ell$ de água); (ii) preparou-se as amostras para a leitura em espectrofotômetro, modelo UV 160 1PC Shimadzu, em comprimento de onda de $760 \mathrm{~nm}$. A amostra foi preparada a partir da retirada de uma alíquota de $0,5 \mathrm{~m} \ell$ da parte superior do tubo de extrações dos fenóis (extrato MCA), a seguir adicionado $0,5 \mathrm{~m} \ell$ de água destilada, mais $0,5 \mathrm{~m} \ell$ do reagente Folin-Ciocalteau misturando-se em vórtex. Após $15 \mathrm{~min}$, foi adicionado $5 \mathrm{~m} \ell$ do reagente alcalino "A" (preparado com carbonato de sódio $2 \%$ em uma solução de hidróxido de sódio $0,1 \mathrm{~N}$ ), e a solução agitada em vórtex. Após 50min foi feita a leitura da absorbância em 760nm em cubetas de $1 \mathrm{~cm}$. Na prova em branco, usou-se água. $\mathrm{O}$ resultado foi expresso em $\mathrm{mg} / \mathrm{g}$ de tecido - peso fresco.

O delineamento experimental utilizado foi o inteiramente casualizado, com três fatores e quatro repetições. Fator $(\mathrm{A})$ : seis porta-enxertos; fator $(\mathrm{B})$ : casca e lenho; fator (C): período de crescimento e dormência. A comparação entre as médias dos tratamentos foi realizada pelo teste de Duncan em nível de $5 \%$ de probabilidade de uso, com o auxílio do programa SANEST (ZONTA et al, 1991).

\section{RESULTADOS E DISCUSSÃO}

Verificaram-se efeitos significativos dos fatores porta-enxertos, tipos de tecidos (casca e lenho), período de crescimento, dormência nos porta-enxertos e da interação entre os mesmos, o que possibilitou estudos comparativos da atividade da peroxidase e dos fenóis totais na casca e no lenho dos porta-enxertos (Tabelas 1 e 2).

Maior atividade das peroxidases na casca dos porta-enxertos foi observado no período de dormência, diferindo do período de crescimento (Tabela 1). Estes resultados estão de acordo com CITADIN (1999), que observou um aumento na atividade das peroxidases em ramos de 7 cultivares de pessegueiro durante o inverno e um decréscimo na atividade da mesma, após a saída de dormência. Desta forma, tem-se procurado relacionar o ponto de máxima atividade das peroxidases com a saída da dormência, em condições de inverno subtropical.

No lenho, tanto no período de crescimento vegetativo como no de dormência, não

Tabela 1 - Médias da atividade das peroxidases e dos fenóis totais na casca e no lenho dos porta-enxertos antes da enxertia, em plantas coletadas no período de crescimento vegetativo e dormência. Pelotas, UFPEL, 2000.

\begin{tabular}{|c|c|c|c|c|c|c|c|c|}
\hline \multirow{3}{*}{ Porta-enxerto } & \multicolumn{4}{|c|}{ Peroxidases UE/min/g tecido peso fresco } & \multicolumn{4}{|c|}{ Fenóis mg/g tecido peso fresco } \\
\hline & \multicolumn{2}{|c|}{ Casca } & \multicolumn{2}{|c|}{ Lenho } & \multicolumn{2}{|c|}{ Casca } & \multicolumn{2}{|c|}{ Lenho } \\
\hline & Cresc. & Dorm. & Cresc. & Dorm. & Cresc. & Dorm. & Cresc. & Dorm. \\
\hline Aldrighi & $13,33 \mathrm{cB}^{*}$ & $33,9 \mathrm{cA}$ & $0,53 \mathrm{aA}$ & $0,28 \mathrm{aA}$ & $159,52 \mathrm{cA}$ & 53,34 bB & $15,75 \mathrm{aA}$ & $9,49 \mathrm{aA}$ \\
\hline Capdeboscq & 7,95 dB & $16,54 \mathrm{eA}$ & $0,57 \mathrm{aA}$ & $0,39 \mathrm{aA}$ & $143,70 \mathrm{cA}$ & $90,45 \mathrm{abB}$ & $16,78 \mathrm{aA}$ & $17,26 \mathrm{aA}$ \\
\hline GF677 & $8,36 \mathrm{~dB}$ & $22,02 \mathrm{dA}$ & $0,64 \mathrm{aA}$ & $0,57 \mathrm{aA}$ & $62,39 \mathrm{dA}$ & 43,12 bA & $8,87 \mathrm{aA}$ & $9,47 \mathrm{aA}$ \\
\hline Mirabolano & $29,23 \mathrm{aB}$ & $72,35 \mathrm{aA}$ & $0,46 \mathrm{aA}$ & $0,80 \mathrm{aA}$ & $519,22 \mathrm{aA}$ & $123,16 \mathrm{aB}$ & $42,16 \mathrm{aA}$ & $11,70 \mathrm{aA}$ \\
\hline Okinawa & $8,19 \mathrm{~dB}$ & $39,67 \mathrm{bA}$ & $0,48 \mathrm{aA}$ & $0,18 \mathrm{aA}$ & $79,09 \mathrm{dA}$ & $43,89 \mathrm{bA}$ & $16,31 \mathrm{aA}$ & $7,51 \mathrm{aA}$ \\
\hline Marianna C. & $18,82 \mathrm{bB}$ & $24,61 \mathrm{dA}$ & $1,19 \mathrm{aA}$ & $0,22 \mathrm{aA}$ & $219,27 \mathrm{bA}$ & $52,27 \mathrm{bB}$ & $31,32 \mathrm{aA}$ & $13,66 \mathrm{aA}$ \\
\hline Média geral & 14,31 & 34,84 & 0,64 & 0,40 & 197,19 & 67,70 & 21,86 & 11,51 \\
\hline $\mathrm{CV}(\%)$ & 23,73 & 26,41 & 28,93 & 25,58 & 24,55 & 11,17 & 24,97 & 31,83 \\
\hline
\end{tabular}

* Médias não seguidas pela mesma letra minúscula, nas colunas, e maiúsculas nas linhas, dentro de cada período de crescimento, diferem entre si pelo teste de Duncan em nível de $5 \%$ de probabilidade erro. 
Tabela 2 - Médias da atividade das peroxidases e dos fenóis totais na casca e lenho dos porta-enxertos antes da enxertia, em plantas coletadas no período de crescimento vegetativo e dormência. Pelotas, UFPEL, 2000.

\begin{tabular}{|c|c|c|c|c|c|c|c|c|}
\hline \multirow{3}{*}{ Porta-enxerto } & \multicolumn{4}{|c|}{ Peroxidases UE $/ \mathrm{min} / \mathrm{g}$ tecido peso fresco } & \multicolumn{4}{|c|}{ Fenóis mg/g tecido peso fresco } \\
\hline & \multicolumn{2}{|c|}{ Crescimento } & \multicolumn{2}{|c|}{ Dormência } & \multicolumn{2}{|c|}{ Crescimento } & \multicolumn{2}{|c|}{ Dormência } \\
\hline & Casca & Lenho & Casca & Lenho & Casca & Lenho & Casca & Lenho \\
\hline Aldrighi & $13,33 \mathrm{~A}^{*}$ & $0,53 \mathrm{~B}$ & $33,9 \mathrm{~A}$ & $0,28 \mathrm{~B}$ & $159,52 \mathrm{~A}$ & $15,75 \mathrm{~B}$ & $53,34 \mathrm{~A}$ & $9,49 \mathrm{~B}$ \\
\hline Capdeboscq & 7,95 A & $0,57 \mathrm{~B}$ & $16,54 \mathrm{~A}$ & $0,39 \mathrm{~B}$ & $143,70 \mathrm{~A}$ & $16,78 \mathrm{~B}$ & $90,45 \mathrm{~A}$ & $17,26 \mathrm{~B}$ \\
\hline GF677 & $8,36 \mathrm{~A}$ & $0,64 \mathrm{~B}$ & $22,02 \mathrm{~A}$ & $0,57 \mathrm{~B}$ & $62,39 \mathrm{~A}$ & $8,87 \mathrm{~B}$ & 43,12 A & $9,47 \mathrm{~B}$ \\
\hline Mirabolano & $29,23 \mathrm{~A}$ & $0,46 \mathrm{~B}$ & $72,35 \mathrm{~A}$ & $0,80 \mathrm{~B}$ & $519,22 \mathrm{~A}$ & $42,16 \mathrm{~B}$ & $123,16 \mathrm{~A}$ & $11,70 \mathrm{~B}$ \\
\hline Okinawa & $8,19 \mathrm{~A}$ & $0,48 \mathrm{~B}$ & $39,67 \mathrm{~A}$ & $0,18 \mathrm{~B}$ & 79,09 A & $16,31 \mathrm{~B}$ & $43,89 \mathrm{~A}$ & $7,51 \mathrm{~B}$ \\
\hline Marianna C. & $18,82 \mathrm{~A}$ & $1,19 \mathrm{~B}$ & $24,61 \mathrm{~A}$ & $0,22 \mathrm{~B}$ & $219,27 \mathrm{~A}$ & $31,32 \mathrm{~B}$ & $52,27 \mathrm{~A}$ & $13,66 \mathrm{~B}$ \\
\hline Média geral & 14,31 & 0,64 & 34,84 & 0,40 & 197,19 & 21,86 & 67,70 & 11,51 \\
\hline $\mathrm{CV}(\%)$ & 23,73 & 28,93 & 26,41 & 25,58 & 24,55 & 24,97 & 11,17 & 31,83 \\
\hline
\end{tabular}

* Médias não seguidas pela mesma letra maiúscula, nas linhas, dentro de cada período de crescimento, diferem entre si pelo teste de Duncan em nível de $5 \%$ de probabilidade.

houve variação entre os porta-enxertos na atividade das peroxidases, que foi baixa (Tabela 1). Comparando-se a atividade das peroxidases entre os tipos de tecidos, observou-se que a casca apresenta maior atividade que o lenho, tanto no período de crescimento vegetativo, como na dormência (Tabela 2). Baseado nestas observações, constatou-se uma maior atividade enzimática presente na casca, por ser uma região de grande atividade meristemática. Esses resultados demonstram ser a zona cambial uma região de maior metabolismo das plantas que facilita a lignificação dos novos tecidos que surgem ou a soldadura da gema no ponto de enxertia.

As maiores atividades das peroxidades são observadas nas paredes celulares e a parede primária representa a matriz na qual ocorre a lignificação, catalisada pela enzima. A atividade também está envolvida no metabolismo de compostos fenólicos atuando no processo de regulação da formação de raízes (SIEGEL, 1993). No presente trabalho, explica-se a maior concentração enzimática, no período de dormência, pela maior lignificação dos tecidos nesta época. Sabe-se que esta enzima atua na biossíntese da lignina.

Diversos autores (GASPAR et al., 1982;

DONALD \& CIPOLLINI, 1998), comentam que as mudanças nas condições ambientais, o ataque de agentes infecciosos (vírus, bactérias e fungos) e injúrias mecânicas induzem e/ou modificam a atividade das peroxidases, as quais, têm este comportamento, como forma de aumentar a capacidade de defesa da planta. Segundo SIEGEL (1993), em condições de estresse, as plantas apresentam alta atividade das peroxidases e freqüentemente, estas são as primeiras enzimas a alterarem a atividade depois da estimulação. Entretanto, pouco se conhece sobre o papel destas no crescimento, desenvolvimento e respostas ao estresse e ao meio ambiente (LAGRIMINI et al., 1990).

KURODA \& SAGISAKA (1998) demonstraram que as catalases e as peroxidases aumentam abruptamente durante os primeiros estágios de aclimatização ao frio. Estes autores sugerem que a catalase está envolvida na remoção de $\mathrm{H}_{2} \mathrm{O}_{2}$, que é produzido durante as reações de síntese de proteínas, organelas e ATP, enquanto as peroxidases contribuem para a formação de $\mathrm{H}_{2} \mathrm{O}_{2}$ requerida para a lignificação da parede celular. Já CITADIN (1999) sugere que esta enzima está relacionada, também, com a destruição da auxina natural, condição essencial para reduzir a atividade celular e de crescimento da planta.

Com relação aos porta-enxertos, observou-se que o Mirabolano apresentou os maiores valores de atividade das peroxidases, diferindo dos demais (Tabela 1), podendo desta forma representar um fator fisiológico e bioquímico de incompatibilidade quando enxertado com cultivares de menor atividade das peroxidases. Estes resultados confirmam aqueles obtidos na prática da enxertia, ou seja, sempre que for enxertado pessegueiro sobre mirabolano, existem sintomas claros de incompatibilidade. Isto confirma as citações de SIMÃO (1998) e SOUTHWICK \& WEIS (1998) que mencionam a incompatibilidade existente nos enxertos de pessegueiro sobre o portaenxerto Mirabolano.

Estudos de SANTAMOUR (1992) concluíram que as diferenças na concentração das 
peroxidases entre o porta-enxerto e o enxerto podem levar a uma lignificação anormal e a uma carência de conexões vasculares na zona do enxerto. Isto sugere que as peroxidases possuem um papel específico na lignificação, porém as generalizações sobre sua função na incompatibilidade devem ser propostas com cautela.

Nos fenóis totais da casca, observou-se o comportamento contrário aquele das peroxidases, quanto aos períodos de crescimento, obtendo-se valores altos no período de crescimento vegetativo e menores no período de dormência, para todos os porta-enxertos. No lenho, entre os períodos de crescimento e entre os porta-enxertos, verificou-se valores baixos e similares entre si (Tabela 1).

Entre a casca e o lenho, os fenóis totais foram maiores na casca para todos porta-enxertos, tanto no período de crescimento quanto na dormência (Tabela 2).

Essa alternância entre fenóis e peroxidases, períodos de crescimento vegetativo e dormência é perfeitamente explicada pela reação enzimática que ocorre entre esses dois compostos. Segundo FRY (1986), as peroxidases utilizam os fenóis, principalmente aqueles de baixo peso molecular, como substrato para síntese de peroxidases, apresentando sempre um balanço inversamente proporcional. Desse modo, sugere-se que tais compostos estão interrelacionados, podendo ser importantes fatores fisiológicos e bioquímicos da compatibilidade da enxertia.

A lignificação da parede celular na planta é formada por polímeros de lignina, os quais contêm compostos fenólicos, nos quais seus radicais são oxidados pelas peroxidases. Este fenômeno, geralmente, ocorre em resposta ao estresse (SIEGEL, 1993), pois atua como um mecanismo de defesa, podendo ser produzido precocemente e evita a penetração de patógenos e/ou, quando já está ocorrendo o ataque, intensifica a formação da peroxidase. Neste evento, encontra-se envolvida principalmente as peroxidases ácidas e parece estar co-relacionada com o decréscimo dos níveis endógenos de auxinas (GASPAR et al., 1982).

\section{CONCLUSÕES}

A atividade das peroxidases e a concentração de fenóis totais variam entre os portaenxertos, período de crescimento e do tipo de tecido do caule. Maior atividade das peroxidases e concentrações de fenóis totais ocorreram nos portaenxertos Mirabolano e Marianna. A atividade das peroxidases e fenóis totais foi maior na casca do que no lenho. No período de dormência, ocorreu maior atividade das peroxidases e menores quantidade de fenóis totais, sendo o inverso no período vegetativo.

\section{REFERÊNCIAS BIBLIOGRÁFICAS}

BIELESKI, R.L., TURNER, N.A. Separation and estimation of amino acids in crude plant extracts by Thin-Layer electrophoresis and chromatography. Analytical Biochemistry, Nova York, v.17, p.278-293, 1966.

CITADIN, I. Necessidade de calor para antese e brotação em pessegueiro Prunus persica L. Batsch. Pelotas, 1999. 74p. Dissertação (Mestrado em agronomia) - Faculdade de Agronomia Eliseu Maciel, Universidade Federal de Pelotas, 1999.

DENCHEVA, A., KLISURKA, D. Interaction between peroxidases and IAA-oxidase in the course of growth and differentiation of the plant cells. Physiologie Végétale, Paris, v.20, n.3, p.385-394, 1982.

DONALD, F., CIPOLLINI, J. The induction of soluble peroxidases activity in bean leaves by wind-induced mechanical perturbation. American Journal of Botany, Lancaster, v.85, n.11, p.1586-1591, 1998.

DRUART, P.H., KEVERS, C.L., GASPAR, T.H. In vitro promotion of root formation by apple shoots through darkness effect on endogenous phenols and peroxidases. Zeitschrift für Pflanzenphysiologie, Stuttgart, v.108, p.429-436, 1982.

FRY, S.C. Polymer-bound phenols as natural substrates of peroxidases. In: GREPPIN, H., PENEL, C., GASPAR, TH., (eds). Molecular and physiological aspects of plant peroxidases. Switzerland : Univ. Genève, 1986. p.169182.

GASPAR, T.H., PENEL, C.L., THORPE, T., et al. Peroxidases: a survey of their biochemical and physiological roles in higher plants. Genève, Université de Genève, Centre de Botanique, 1982. 313p.

HARKIN, J.M., OBST, J.R. Lignification in trees. Indication of exclusive peroxidases participation. Science, Washington, v.180, p.296-298, 1973.

JENNINGS, A.C. The determination of dihydroxy phenolic compounds in extracts of plant tissues. Analitycal Biochemistry, Nova York, n.118, p.396-398, 1981.

KURODA, H., SAGISAKA, S. Metabolic and enzymatic responses associated with oxidative stress in plants acclimatized to cold environments. Recent Research Developments in Agricultural \& Biological Chemistry, Nova York, v.2, p.395-410, 1998.

LAGRIMINI, L.M., BRADFORD, S., ROTHSTEIN, S. Peroxidases-induced wilting in transgenic tobacco plants. The Plant Cell, Rockville, v.2, p.7-18, 1990.

MATSUNO, H., URITANI, I. Physiological behavior of peroxidases isozymes in sweet potato root tissue injured by cutting or with black rot. Plant \& Cell Physiology, Tokyo, v.13, p.1091-1101, 1972.

MUSACCHI, S. Aspetti biochimici della disaffinità d́nnesto. Dipartimento di Colture Arboree - Università di Bologna. Rivista di Frutticoltura, Bolonha, n.3, p.73-79, 1994. 
SANTAMOUR, F.S.Jr. Predicting graft incompatibility in woody plants. Combined Proceedings International Plant Propagators'Society, Nova York, v.42, p.131-134, 1992.

SIEGEL, B.Z. Plant peroxidases - an organismic perspective review. Plant Growth Regulation, Nova York, v.12, p.303$312,1993$.

SIMÃO, S. Tratado de fruticultura. Piracicaba : Fundação de
Estudos Agrários Luiz de Queiroz - FEALQ, 1998. 760p.

SOUTHWICK, S.M., WEIS, K.G. Selecting and propagating rootstocks to produce apricots. Hortechnology, Chicago, v.8, n.2, p.164-170, 1998

ZONTA, E.P.; MACHADO, A.A. Manual do SANEST: Sistema de Análise Estatística para Microcomputadores. Pelotas : UFPEL, 1991. 102p. 